\title{
Head and Neck Lymphomas in HIV Patients: a Clinical Perspective
}

\author{
Natsuki Oishi ${ }^{1,2}$ José Vicente Bagán ${ }^{3} \quad$ Karla Javier $^{4}$ \\ ${ }^{1}$ ENT Department, Consorci Hospital General Universitari de Valencia, \\ Valencia, Spain \\ 2 ENT Department, Universitat de Valencia Facultat de Medicina i \\ Odontologia, Valencia, Comunitat Valenciana, Spain \\ ${ }^{3}$ Department of Stomatology, Consorci Hospital General Universitari \\ de Valencia, Valencia, Comunitat Valenciana, Spain \\ ${ }^{4}$ Department of Haematology, Consorci Hospital General Universitari \\ de Valencia, Valencia, Comunitat Valenciana, Spain
}

Int Arch Otorhinolaryngol 2017;21:399-407.

\author{
Enrique Zapater $^{1}$
}

\begin{abstract}
Address for correspondence Natsuki Oishi, ENT Department, Consorci Hospital General Universitari de Valencia, Avda. Tres Cruces s/n Valencia 46014, Spain (e-mail: dramiriamoishi@gmail.com).
\end{abstract}

\begin{abstract}
Keywords

- HIV

- lymphoma

- head and neck neoplasms

Introduction Because of the many HIV-related malignancies, the diagnosis and treatment of lymphoma in patients infected with human immunodeficiency virus are challenging.

Objective Here, we review current knowledge of the pathogenesis, epidemiology, symptomatology, diagnosis, and treatment of head and neck lymphomas in HIV patients from a clinical perspective.

Data Synthesis Although Hodgkin's lymphoma is not an AIDS-defining neoplasm, its prevalence is ten times higher in HIV patients than in the general population. NHL is the second most common malignancy in HIV patients, after Kaposi's sarcoma. In this group of patients, NHL is characterized by rapid progression, frequent extranodal involvement, and a poor outcome. HIV-related salivary gland disease is a benign condition that shares some features with lymphomas and is considered in their differential diagnosis.

Conclusion The otolaryngologist may be the first clinician to diagnose head and neck lymphomas. The increasing survival of HIV patients implies clinical and epidemiological changes in the behavior of this disease. Early diagnosis is important to improve the prognosis and avoid the propagation of HIV infection.
\end{abstract}

\section{Introduction}

T and B lymphocytes are the main cells of the immune system. In healthy people, they are mainly located in the lymphoid organs (lymphatic nodes and spleen) and in mucosa-associated lymphoid tissue (MALT). The head and neck region is rich in lymphoid tissue, especially Waldeyer's ring, the thyroid, the salivary glands, and the oral cavity. There are also several chains of regional lymph nodes. Therefore, the head and neck are fertile anatomic sites for the development of lymphoproliferative diseases, in which malignant neoplastic mutations occur in normal lymphoid tissue and give rise to a lymphoma. In the head and neck, malignant lymphomas account for $5 \%$ of all malignant neoplasms. ${ }^{1}$

received

July 16, 2016

accepted

October 31, 2016

published online

February 1, 2017
Virus-linked cancers are responsible for $15 \%$ of the total incidence of malignant neoplasms. ${ }^{2}$ Patients infected with human immunodeficiency virus (HIV) are at a higher risk than the uninfected population of developing a malignancy. The most frequent HIV-associated malignant neoplasm of the head and neck is Kaposi's sarcoma, followed by lymphoma. Thus, lymphoma is regarded as an opportunistic neoplasm due to its similarities with the opportunistic infections that occur in immunosuppressed patients. ${ }^{3}$ This feature is among the criteria used to establish the AIDS stage also CD4+ T cell count $<200 / \mu \mathrm{L} .{ }^{4}$ What is clear is that specific lymphoma subtypes are caused by one or both herpesviruses of the

Copyright (c) 2017 by Thieme Revinter Publicações Ltda, Rio de Janeiro, Brazil
DOI https://doi.org/

10.1055/s-0036-1597825. ISSN 1809-9777.
License terms

(이 (1) $\Theta \circledast$ 
gamma subfamily: Epstein Barr virus (EBV/HHV-4) and Kaposi's sarcoma herpesvirus (KSHV/HHV-8). The EVB infection occurs in $40 \%$ of Large Cell Lymphomas (LCL) and in $90 \%$ of Immunoblastic Lymphomas (IBL) cases. ${ }^{5}$ Plasmablastic lymphoma (PBL) nearly always occur in HIV positive patients, in whom they preferentially localize in the oral mucosa; and are strongly associated with infection by HHV8 and EBV. ${ }^{6}$

Because of the many HIV-related malignancies, the diagnosis and treatment of lymphoma in HIV patients are challenging. In this article, we summarize current knowledge of HIV-related head and neck lymphomas, focusing on a clinical perspective.

\section{Literature Review}

\section{Pathology}

In 2008, the World Health Organization proposed a classification system for lymphomas that distinguished six groups: precursor lymphoid neoplasms, mature B cell neoplasms, mature T- and natural killer (NK)-cell neoplasms, Hodgkińs lymphoma, Immunodeficiency-associated lymphoproliferative disorders, and histiocytic and dendritic cell neoplasms. ${ }^{7}$

Non-Hodgkin's lymphoma (NHL) is the most frequent tumor of the head and neck, accounting for $~ 75 \%$ of lymphomas in this anatomic region. ${ }^{1}$

In HIV patients, most lymphomas are derived from B-cells, with the most common NHLs being immunoblastic large-cell lymphomas and diffuse large B cell lymphomas (DLBCLs). Both tumors generally occur in the context of moderate to severe immunosuppression $\left(\mathrm{CD}^{+}\right.$cell count $<100 \mathrm{~mm}^{3} / \mathrm{ml}$ ) and they are often associated with EBV. ${ }^{8}$ Together with Burkitt's lymphomas and Burkitt's-like lymphomas, they serve as indicators in the staging of AIDS. ${ }^{9}$

\section{Epidemiology}

Epidemiological studies have shown that Hodgkin's lymphomas and NHLs are the most common tumors in HIV patients. Both are usually diagnosed at an early stage of HIV infection, when $\mathrm{CD} 4{ }^{+}$cell counts are relatively high. ${ }^{10} \mathrm{HIV}$ patients are at a 60 - to 200 -fold greater risk than the general population of developing $\mathrm{NHL}^{11,12}$.
Immunosuppression related to HIV facilitates virus-induced carcinogenesis. Type 8 human herpes virus (HHV-8), EBV, and human papilloma virus have all been related to the development of Kaposi's sarcoma. ${ }^{13}$ Nearly half of all cases of lymphoma in HIV patients are associated with concomitant infection with gamma herpes virus, EBV, or HHV-8. ${ }^{8}$ Recent findings are consistent with a role of HIV as a critical microenvironmental factor promoting lymphoma development. These data are changing the current paradigm, which assumes that HIV is only indirectly related to lymphomagenesis. ${ }^{14}$

Antiretroviral treatment has led to a decline in the incidence of opportunistic infections and, thus, to an increase in the survival of HIV patients. Within this group, there has been a decrease in the incidence of Kaposis sarcoma, whereas similar declines in Hodgkin's lymphoma and NHL have yet to be confirmed. ${ }^{15,16}$

\section{Symptomatology and Examination}

It is important to carefully examine every neck node suggesting malignancy, as it can be the first manifestation of a cancer located in the head and neck. Using endoscopic techniques, the otolaryngologist is able to locate tumors in difficult-to-examine areas such as the nasopharynx, larynx, and hypopharynx.

The most frequent location of a lymphoma in an HIV patient is the neck (50\%), followed by the central nervous system, oral cavity, pharynx, parotid gland, mandible, paranasal sinuses, larynx, and orbit ${ }^{17,18}$ (- Table 1). Lymphomas in the HIV-infected population develop in relatively young patients and may be the first disease to awaken a suspicion of HIV infection. Indeed, the diagnosis of head and neck lymphoma should always include the exclusion of HIV. ${ }^{17}$ Conversely, the mean time from the diagnosis of HIV to lymphoma development is 1.5 years. $^{18}$

Lymphomas in HIV patients generally manifest with atypical symptoms. The characteristic aggressiveness of these tumors and their typically advanced stage at diagnosis reflect the deterioration of immunity, increased viral load, and low $\mathrm{CD}^{+}$ lymphocyte counts. ${ }^{18,19}$ In addition, as noted above, HIV-related lymphoma generally occurs together with opportunistic infections such as Pneumocystis carinii pneumonia, candidiasis, cytomegalovirus retinitis, and herpes zoster. Lymphomas can

Table 1 Table of the most common location, characteristics, and types of head and neck lymphoma in HIV patients

\begin{tabular}{|l|l|l|}
\hline Location & Characteristics & Types \\
\hline Neck & $\begin{array}{l}\text { The most frequent location in an HIV patient. } \\
\text { Multiple painless nodes }\end{array}$ & $\begin{array}{l}\text { Burkitts lymphoma, Immunoblastic lymphoma, } \\
\text { large-cell lymphoma }\end{array}$ \\
\hline Oral cavity & $\begin{array}{l}\text { Tumour or ulcerated lesion located especially } \\
\text { at the gingivae, palate and tongue }\end{array}$ & $\begin{array}{l}\text { Plasmablastic lymphoma, a B cell lymphoma with } \\
\text { a high proportion of plasmablastic lymphocytes }\end{array}$ \\
\hline Pharynx: Waldeyeŕs ring & $\begin{array}{l}\text { The palatine tonsil is the most common site. } \\
\text { Dysphagia, sore throat, asymptomatic } \\
\text { enlargement of one tonsil. }\end{array}$ & $\begin{array}{l}\text { Diffuse large B cell, folliular, Burkitt́s, and mantle } \\
\text { cell lymphomas }\end{array}$ \\
\hline Parotid gland & $\begin{array}{l}\text { Unilateral enlargement in the } \\
\text { absence of facial paresis. } \\
\text { A benign lymphoepithelial lesion (BLL) } \\
\text { should be considered in the differential } \\
\text { diagnosis of parotid lymphoma }\end{array}$ & $\begin{array}{l}\text { Marginal-zone B cell lymphoma of the MALT, } \\
\text { follicular lymphomas, } \\
\text { diffuse large B cell lymphomas }\end{array}$ \\
\hline
\end{tabular}


also coexist with Kaposis sarcoma, but, although the latter may regress when the immune system recovers, this is not the case with lymphoma. ${ }^{18}$

Given the relative infrequency in the general population of Hodgkin's lymphoma in the head and neck, systemic symptoms, apart from those deriving from HIV infection, are uncommon but may consist of fever, night sweats, or pruritus.

Involved neck nodes in lymphoma are usually multiple and painless. They are not as hard on palpation as the metastatic nodules of squamous cell carcinoma and do not adhere to either the skin or deep tissue planes. The most common location of affected nodes is the lower region of the neck, but the axilla and groin may also be involved. ${ }^{20}$ It is important to emphasize that nodal-based lymphomas may be difficult to identify in patients with the persistent generalized lymphadenopathy that characterizes HIV.

Extranodal manifestations are a common clinical presentation in HIV-associated lymphomas. In the general population with NHL, extranodal involvement occurs in $24-48 \%$ of cases; $10 \%$ of these involve the head and neck region. ${ }^{21,22}$ Primary extranodal Hodgkińs disease is rare. NHL in the head and neck, at the beginning, is usually submucosal rather than ulcerative, as seen in squamous cell carcinoma. Disease evolution can lead to ulceration. ${ }^{23}$ Half of the extranodal lymphomas of the head and neck are located in Waldeyeŕs ring. The involvement of this location is associated with an increased incidence of disease spread to the gastrointestinal tract. The palatine tonsil is the most common site of lymphoma development; it accounts for the typical symptoms of dysphagia and sore throat. Because the asymptomatic enlargement of one tonsil is common, some authors consider routine excision of abnormally large asymmetrical tonsils to be advisable ${ }^{24}$ (- Fig. 1).

Cavum lymphoma against a background of HIV is usually diagnosed from an enlarged neck node. Thus, prior to a surgical procedure, the detection of any neck adenopathy should be followed by an endoscopic examination of the upper cavities. ${ }^{20}$

Oral lymphomas occur more frequently in patients with HIV infection. Typical symptoms include oral swelling, pain, and ulcers. These lymphomas may present as a tumor or ulcerated lesion located anywhere in the mouth, but especially the gingivae, palate,

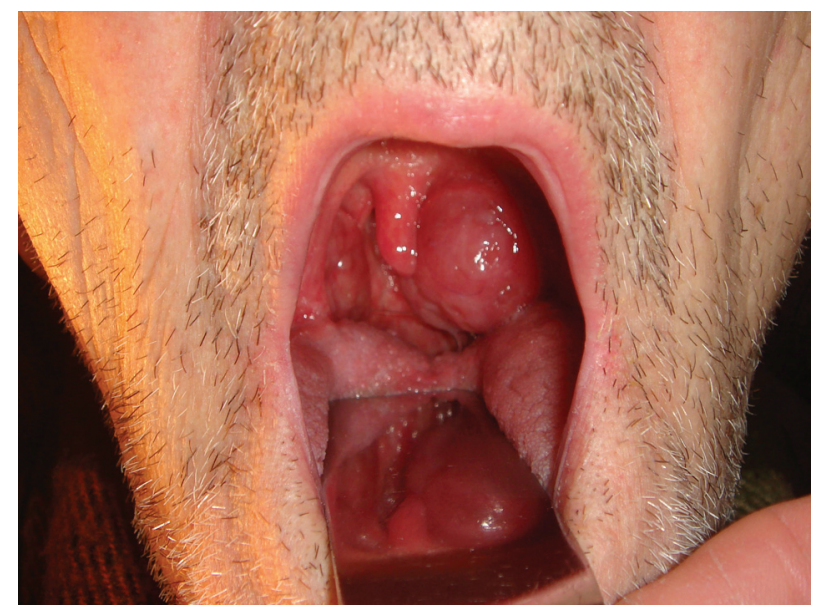

Fig. 1 Unilateral tonsillar hypertrophy in diffuse large B cell lymphoma.

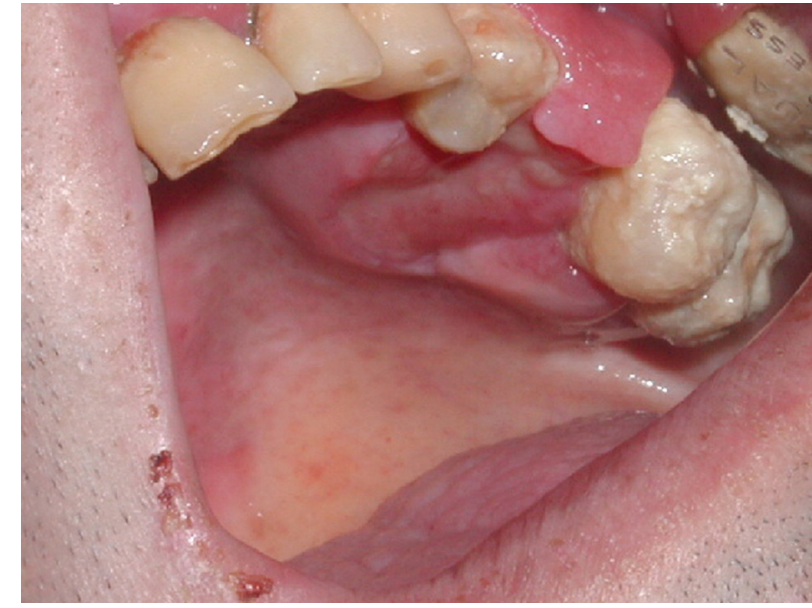

Fig. 2 Ulceration of the gingivae.

and tongue. ${ }^{25,26}$ Plasmablastic lymphoma, a B cell lymphoma with a high proportion of plasmablastic lymphocytes, is the most common HIV-associated subtype in this location. ${ }^{15,27}$ Constitutional symptoms such as fever and night sweats are frequent in PBL. Its typical appearance is a nonspecific ulceration that spreads rapidly and may eventually lead to hemorrhage, necrosis, and lytic bone destruction. A possible explanation for the high frequency of PBL in lymphoid areas of Waldeyer's ring and in epithelial cells of the cavum and oropharynx is the predilection of EBV to accumulate at these $\operatorname{sites}^{28}$ (-Fig. 2).

Laryngeal lymphoma in HIV patients is usually located in the supraglottic region and therefore typically first manifests as dysphagia, although with disease evolution hoarseness and dyspnea may also develop. HIV patients with pharyngo-laryngeal symptoms should always be examined by an otolaryngologist, who will be able to detect lesions in difficult-to-examine locations. This is particularly important because an early diagnosis is essential to improve the prognosis. ${ }^{29}$

\section{Diagnosis}

The diagnosis of lymphoma is best made based on the pathology results (-Fig. 3). In nodal disease, a complete adenectomy is required. If the neck node is located at superficial planes, which is the most frequently involved site, the procedure can be performed under local anesthesia with or without sedation. It is important to resect the node completely and to preserve it as undistorted as possible. In extranodal disease, a deep biopsy should be taken. The biopsy site should be close to healthy mucosa/skin to avoid necrotic tissue. Local anesthesia is possible in patients with lesions in the oral cavity, oropharynx or nasopharynx and with some supraglottic and hypopharyngeal lesions. In salivary gland tumors as well as thyroid and some laryngeal and hypopharyngeal lesions, general anesthesia is required. Biopsy material should be processed fresh to allow immunohistochemical staining, which is necessary for an accurate diagnosis.

The results of a blood analysis will not be specific for lymphoma but will instead detect neutrophilia, eosinophilia, lymphopaenia, thrombocytosis, thrombocytopaenia, or anemia. Neutrophilia, lymphopaenia and anemia are considered 


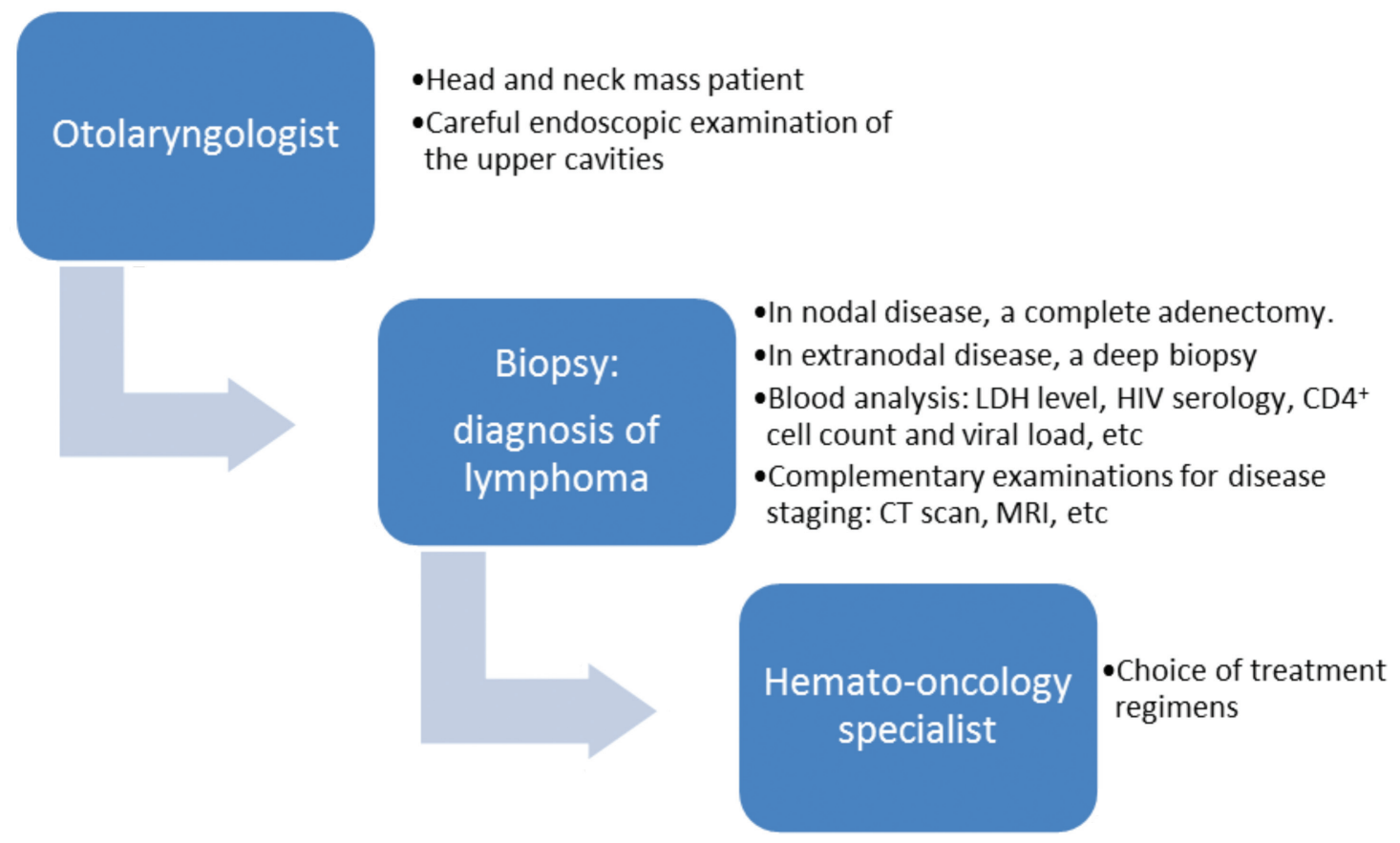

Fig. 3 Algorithm of a recommended diagnostic workup.

signs of a poor prognosis in lymphoma patients. Increases in serum alkaline phosphatase and calcium levels may indicate bone infiltration. Liver and kidney analytical indicators should also be measured.

Bone marrow involvement is more common in patients with immunodeficiency and in patients with advanced stage disease, less favorable histologic types, or constitutional symptoms. A bone marrow biopsy is recommended for all patients with B symptoms, advanced disease stages, bulky disease, or peripheral blood cytopaenias.

Complementary examinations are indicated only for purposes of disease staging (-Table 2 ).

Radiological studies are useful to assess tumor extension; whereas thorax radiography and CT are necessary. Thorax, abdominal, and pelvic CT scans are compulsory; however, abdominal scans will not accurately detect retroperitoneal, liver, or spleen involvement. Orthopantomography and CT scanning of the cranial base, paranasal sinuses, and maxilla are useful to detect bone invasion in the proximity of an extranodal lymphoma (-Fig. 4 ).

Magnetic resonance imaging (MRI) are used to study soft tissues, including the parapharyngeal space, tongue, bone marrow, and brain. ${ }^{20} \mathrm{~A}$ typical finding is homogeneous lymph nodes that are increased in size, well-defined, rounded, ovoid, or lobed. ${ }^{30}$ Nodal involvement in Hodgkin's lymphoma is continuous and usually affects the internal jugular chain. Necrosis of the neck nodes or extranodal extension is often seen in patients with aggressive lymphoma. ${ }^{31}$ Node calcifications are often apparent after chemotherapy or irradiation. ${ }^{30}$

${ }^{67} \mathrm{Ga}$ scintigraphy is used to evaluate disease extension and to monitor the effectiveness of treatment. However, there may be false-positives if there is active infection and falsenegatives after recent chemotherapy treatment (minimum 3 weeks) in necrotic areas or in lesions $<2 \mathrm{~cm}$ in diameter. PET

Table 2 Ann Arbor staging system for lymphomas

\begin{tabular}{|l|l|}
\hline Stage I & Involvement of a single lymph node region (I) or localized involvement of a single extralymphatic organ site (IE). \\
\hline Stage II & $\begin{array}{l}\text { Involvement of two or more lymph node regions on the same side of the diaphragm (II) or localized } \\
\text { involvement of an extralymphatic organ or site and one or more lymph node regions on the same side of } \\
\text { the diaphragm (IIE) }\end{array}$ \\
\hline Stage III & $\begin{array}{l}\text { Involvement of lymph node regions on both sides of the diaphragm (III), which may also be a accompanied by } \\
\text { localized involvement of an associated extralymphatic organ or site (IIIE), by involvement of the spleen (IIIS), } \\
\text { or both (IIIS + E) }\end{array}$ \\
\hline Stage IV & $\begin{array}{l}\text { Diffuse or disseminated involvement of one or more extralymphatic organs or tissues, with or without } \\
\text { associated lymph node involvement, or isolated extralymphatic organ involvement with distant } \\
\text { (none-regional) nodal involvement. }\end{array}$ \\
\hline
\end{tabular}




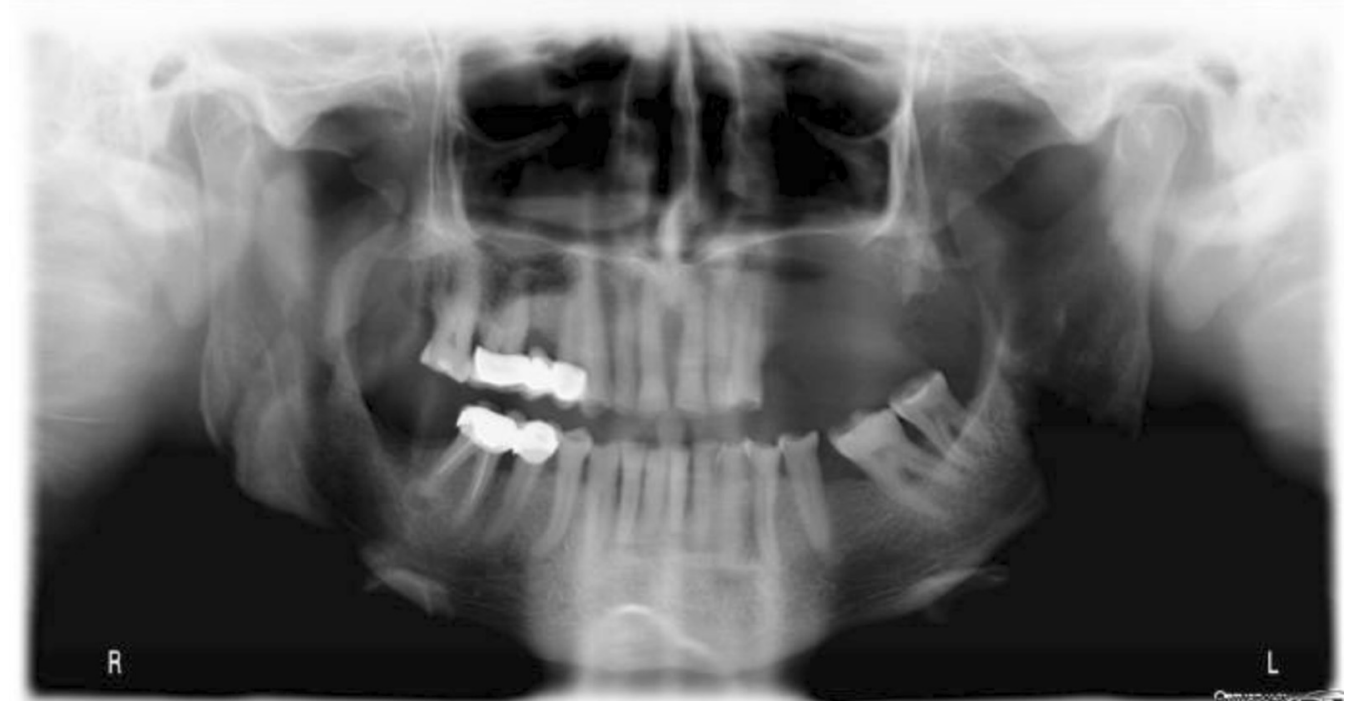

Fig. 4 Wide maxillary lysis in a patient with gingival lymphoma.

is the standard for staging in aggressive lymphomas and HL. PL is performed as part of staging in ARL and is used to identify lymphoma cells and to perform a PCR for EBV.

\section{Treatment}

The introduction of highly active antiretroviral therapy (ART) in HIV-infected patients, together with the administration of prophylactic antibiotics to prevent infections and of hematopoietic factors, has changed the prognosis of patients with HIV-related lymphoma. Thus, today the outcome of these patients is comparable to that of the population with nonHIV-related lymphoma. The optimal therapy for lymphomas in the setting of HIV has yet to be defined. ART is administered initially and may be later modified to control HIV infection and allow chemotherapy and/or radiation therapy. The choice of therapy is determined by the histopathologic subtype and stage of the disease; however, in HIV patients, modifications should be made based upon the degree of virus-linked immunosuppression, as measured by the $\mathrm{CD} 4^{+}$cell count. ${ }^{32}$

The therapeutic approach will depend on the subtype of HIV-associated lymphoma, as described below.

DLBCL: HIV-positive patients with DLBCL usually present with the disease in advanced stages. For most of these patients, combination chemotherapy with CHOP (cyclophosphamide, doxorubicin, vincristine, and prednisone) is recommended; the addition of immunotherapy with rituximab in those with CD20-positive disease and in whom the $\mathrm{CD}^{+}$cell count is $>50$ cells $/ \mu \mathrm{l}$, has been suggested. ${ }^{33,34}$ In patients with CD20-positive disease and a CD4 ${ }^{+}$cell count $<50$ cells/ $/ \mathrm{l}$, the decision to add rituximab must be made on a patientspecific basis. For patients with disease characterized by a high tumor-cell growth fraction $\left(K_{\mathrm{i}} 67>80 \%\right)$ or plasmablastic histology, dose-adjusted (DA) EPOCH (etoposide, vincristine, doxorubicin, oral prednisone, and an intravenous bolus of cyclophosphamide) plus rituximab is recommended. ${ }^{35,36}$ This choice of treatment requires prophylaxis for Pneumocystis jirovecii pneumonia and antibiotic prophylaxis for enteric organisms. Antiviral and antifungal prophylaxis can also be instituted. When the paranasal sinuses, epidural space, or bone marrow are involved, or if disease involvement includes more than two extranodal sites, lumbar puncture should be performed as part of the diagnostic workup.

Burkitt's lymphoma: For most patients with AIDS-related Burkitt's lymphoma, CDE (cyclophosphamide, doxorubicin, and etoposide) plus rituximab is the recommended treatment. ${ }^{37-39}$ Hyper CVAD (cyclophosphamide, vincristine, doxorubicin, and dexamethasone, alternating with highdose methotrexate and cytarabine) plus rituximab ${ }^{40-42}$ and modified CODOX-M/IVAC (cyclophosphamide, doxorubicin, vincristine, methotrexate, intrathecal cytarabine and methotrexate/ifosfamide, etoposide, cytarabine and intrathecal methotrexate) are the suggested chemotherapeutic regimens. ${ }^{43-45}$ For patients who may not tolerate these highly toxic regimens, alternative treatment with DA EPOCH plus rituximab may be considered. For all patients with a $\mathrm{CD} 4^{+}$cell count $<100$ cells $/ \mu l$, tumor elimination using rituximab should be considered. During treatment, ART should be continued along with $P$. jirovecii antifungal prophylaxis as well as antivirals. All patients should receive granulocyte colony stimulating factor and undergo lumbar puncture. They should also be administered intrathecal chemotherapy and high doses of antineoplastic agents that cross the bloodbrain barrier. Patients treated with short, intensive chemotherapeutic regimens such as CODOX-M/IVAC can delay ART until after they have completed chemotherapy.

PBL: The same regimens recommended for Burkitt's lymphoma are recommended for PBL. In this group of patients, intrathecal chemotherapy is an option given the high rates of proliferation and extranodal involvement, the strong association of PBL with HIV infection, and the presence of MYC translocations. The role of radiotherapy is not clear, as there are only 20-30 reported cases in which PBL patients underwent radiotherapy. In patients with chemotherapy-sensitive PBL, autologous stem cell transplantation during the first 
remission is a treatment option that may increase overall survival. ${ }^{46}$ Because of the plasmablastic differentiation of PBL cells, patients have been administered antimyeloma agents, including bortezomib in combination with chemotherapy, in those with disease relapse; however, this approach may be of limited efficacy. ${ }^{47}$

Primary effusion lymphoma: The prognosis of these patients is extremely poor, and combination ART has shown little impact on this lymphoma subtype. The most common therapeutic regimens used in patients with primary effusion lymphoma are CHOP-like therapies in association with rituximab. DA EPOCH and CDE are usually well tolerated and effective. Bortezomib and lenalidomide have also been tested in patients with primary effusion lymphoma, but favorable results have yet to be reported. ${ }^{48}$ This subtype has been related to HHV-8 infection, which is why complete remission has been achieved in patients administered the antiviral nucleotide analogue cidofovir, which is effective in the lytic phase of HHV-8/Kaposi's sarcoma-associated herpesvirus replication. ${ }^{49-51}$

Relapsed lymphoma is associated with a poor prognosis; the median survival of these patients is usually $<1$ year. For patients with relapsed NHL of B cell origin, a good second-line treatment is ESHAP (etoposide, methylprednisolone, cytarabine, and cisplatin). In addition, given the significant improvements in HIV control and immune function, autologous stem cell transplantation can be a therapeutic option in select patients with relapsed lymphoma, as is the case in their HIVnegative counterparts.

Hodgkin's lymphoma: All patients with Hodgkin's lymphoma should be treated with potent ART and a standard chemotherapeutic regimen such as ABVD (adriamycin, bleomycin, vinblastine and dacarbazine) or BEACOPP (bleomycin, etoposide, doxorubicin, cyclophosphamide, vincristine, procarbazine, and prednisone) as the initial treatment, followed by field radiation therapy. ${ }^{52}$

Early relapsed ( $<1$ year) disease must be treated with drugs different than those used in the first-line treatment. One option is MOPP (nitrogen mustard, vincristine, procarbazine, and prednisone). If relapse occurs later, the same regimen can be used. However, a better strategy is to achieve a second complete remission followed by consolidation treatment with autologous stem cell transplantation.

NK-/T cell lymphoma: For localized disease, the currently preferred standard approach is radiotherapy together with chemotherapy because systemic relapse rates are as high as 25-40\%, which suggests that apparently localized nasal NK-/T cell lymphomas can indeed become disseminated. Plane radiotherapy with MRI or PET/CT should be used to ensure coverage of all involved areas. The delivered dose of radiation should not be $<50 \mathrm{~Gy}$; lower doses will result in high in-field failure rates. ${ }^{53,54}$ CHOP-based chemotherapy is not recommended for patients with NK-/T cell lymphoma. The regimens most often used with radiotherapy with a very good overall response, complete response, and survival rates are those based on alkylating agents such as $2 / 3$ DeVIC (dexamethasone, etoposide, ifosfamide, and carboplatin) or VIPD (etoposide, ifsofamide, cisplatin, and dexamethasone) or on L-asparagi- nase, including LVP (L-asparaginase, vincristine, and prednisone), GELOX (gemcitabine, Escherichia coli L-asparaginase, and oxaliplatin) or SMILE (dexamethasone, methotrexate, ifosfamide, $E$. coli $\mathrm{L}$-asparaginase, and etoposide). ${ }^{55-58}$

\section{Prognostic Factors}

Lymphomas in HIV patients have frequent extranodal involvement, in which case the prognosis is poor. ${ }^{12}$ Indolent lymphomas are often diagnosed in HIV patients, and the incidence of these tumors is expected to increase. Indolent lymphomas arising in infected patients are different from intermediate- and high-grade lymphomas in terms of the features of the underlying HIV disease, as they develop in patients with relatively preserved $\mathrm{CD}^{+}$cell counts. Prolonged survival and a propensity for bone marrow involvement are common features of low-grade lymphomas, just as in uninfected patients. ${ }^{59}$

The International Prognostic Index (IPI) is a widely accepted measure to assess the prognosis of patients with aggressive lymphomas, and it is also relevant for those with HIV-associated lymphomas. The IPI categorises patients into low-, intermediateand high-risk groups according to the baseline characteristics of age, Eastern Cooperative Oncology Group (ECOG) performance status (PS), lactate dehydrogenase (LDH) level, Ann Arbor stage, and extranodal involvement. ${ }^{60}$ The age-adjusted IPI (aaIPI) stratifies prognosis based on age ( $<60$ versus $\geq 60$ years) and relies solely on stage, PS, and LDH level. ${ }^{61}$

\section{Discussion}

For a minority of cases, the otolaryngologist is the first physician to see an HIV patient due to the frequent head and neck manifestations of the disease. ${ }^{62}$ It is estimated that $>40 \%$ of HIV patients have symptoms related to the ear, nose, and throat region, including unusual recurrent infections or malignancies. The correct diagnosis of HIV will be facilitated by a recognition of its relationship to these conditions. ${ }^{63}$

During surgical procedures involving HIV patients for biopsy, surgeons must take adequate measures to avoid HIV transmission to surgical personnel. Numerous epidemiological studies have shown that the overall risk of HIV transmission during surgical procedures is low, but it is not zero. The risk of HIV transmission after percutaneous exposure to HIV-infected blood is $\sim 0.3 \%{ }^{64}$ and after mucous membrane exposure $\sim 0.09 \% .{ }^{65}$ Nevertheless, there is still a need for wider adoption of safer surgical techniques and better personal protective equipment to reduce the chance of HIV transmission in the operating theater. One method known to reduce risk is double gloving during surgery. ${ }^{66}$ There is also low-quality evidence that triple gloving and the use of special gloves can further reduce the risk of glove perforations compared with double gloving with gloves made out of typical materials. ${ }^{67}$ The use of blunt needles appreciably reduces the risk of exposure to contaminated blood and body fluids by surgeons and their assistants. ${ }^{68}$ When exposure does occur, immediate evaluation and the initiation of post-exposure prophylaxis, when indicated, can substantially reduce the risk of HIV transmission. Whenever possible, the HIV status of the patient should be 
determined to guide appropriate use of HIV post-exposure prophylaxis. $^{69}$

Lymphoma of the salivary glands accounts for 2-5\% of salivary gland neoplasms. The parotid gland is the most frequently affected; patients show unilateral enlargement in the absence of facial paresis on examination. ${ }^{20} \mathrm{~A}$ benign lymphoepithelial lesion (BLL) should be considered in the differential diagnosis of parotid lymphoma. In fact, BLL is the most common parotid tumor in HIV patients, in whom the prevalence is $10 \%$; by contrast, it is sporadic in the general population $(<1 \%) .{ }^{70}$ Thus, a diagnosis of BLL should trigger a suspicion of AIDS. ${ }^{71}$ Malignant lymphomas of the parotid gland are thought to arise in BLL lesions; thus, this benign condition may progress to malignant lymphoma. BLL can therefore be considered a transitional lesion. ${ }^{72}$ The most frequent histopathological forms are marginal-zone B cell lymphoma of the MALT type, follicular lymphomas, and diffuse large B cell lymphomas. ${ }^{30}$

Barta et $\mathrm{al}^{73}$ created the HIV-Related Lymphoma IPI (ARL-IPI), a new prognostic index to assess the risk of death in patients with AIDS-related lymphomas. The ARL-IPI was based on 487 patients newly diagnosed with HIV-related lymphomas who were evaluated for pretreatment features. Survival following treatment with rituximab-containing chemoimmunotherapy was then predicted. The index considers age, sex, ECOG performance status, $\mathrm{CD}^{+}$cell count, and viral load at diagnosis, history of any AIDS-defining illness prior to NHL diagnosis, type of lymphoma, Ann Arbor stage, LDH level, number of involved extranodal sites, and type of chemotherapy. The authors found that the ARL-IPI performed significantly better than the age-adjusted IPI in predicting the risk of death and better discriminated the risk of death between each risk category.

\section{Final Comments}

The otolaryngologist may be the first clinician to diagnose head and neck lymphomas. Detecting a neck node requires an endoscopic examination of the whole upper aero-digestive tract to rule out a primary tumor. The diagnosis of extranodal NHL should also exclude HIV infection. Lymphomas in the HIV-positive population develop at early ages, are generally very aggressive, and are diagnosed at an advanced stage. Patients with HIV-associated lymphoma will often also have opportunistic infections such as $P$. jirovecii pneumonia, candidiasis, cytomegalovirus retinitis, and herpes zoster. The increasing survival of HIV patients implies clinical and epidemiological changes in the behavior of this disease. Early diagnosis is important to improve the prognosis and avoid the propagation of HIV infection.

\section{References}

1 Boring CC, Squires TS, Tong T. Cancer statistics, 1993. CA Cancer J Clin 1993;43(1):7-26

2 zur Hausen H. Viruses in human cancers. Science 1991;254(5035) $1167-1173$
3 Ioachim HL. Immunopathogenesis of human immunodeficiency virus infection. Cancer Res 1990;50(17, Suppl)5612S-5617S

4 Centers for Disease Control. Revisions of the CDC surveillance case definition for adquired immunodeficiency syndrome. MMWR 1987;36:1-15

5 Carbone A, Tirelli U, Gloghini A, Volpe R, Boiocchi M. Human immunodeficiency virus-associated systemic lymphomas may be subdivided into two main groups according to Epstein-Barr viral latent gene expression. J Clin Oncol 1993;11(9):1674-1681

6 Cioc AM, Allen C, Kalmar JR, Suster S, Baiocchi R, Nuovo GJ. Oral plasmablastic lymphomas in AIDS patients are associated with human herpesvirus 8. Am J Surg Pathol 2004;28(1):41-46

7 Jaffe ES, Harris NL, Stein H, Isaacson PG. Classification of lymphoid neoplasms: the microscope as a tool for disease discovery. Blood 2008;112(12):4384-4399

8 Carbone A. AIDS-related non-Hodgkin's lymphomas: from pathology and molecular pathogenesis to treatment. Hum Pathol 2002; 33(4):392-404

9 Goedert JJ. The epidemiology of acquired immunodeficiency syndrome malignancies. Semin Oncol 2000;27(4):390-401

10 Tirelli U, Errante D, Dolcetti R, et al. Hodgkin's disease and human immunodeficiency virus infection: clinicopathologic and virologic features of 114 patients from the Italian Cooperative Group on AIDS and Tumors. J Clin Oncol 1995;13(7):1758-1767

11 Beral V, Peterman T, Berkelman R, Jaffe H. AIDS-associated nonHodgkin lymphoma. Lancet 1991;337(8745):805-809

12 Tirelli U, Spina M, Gaidano G, Vaccher E, Franceschi S, Carbone A. Epidemiological, biological and clinical features of HIV-related lymphomas in the era of highly active antiretroviral therapy. AIDS 2000;14(12):1675-1688

13 Bower M, Stebbing J. AIDS-associated malignancies. Cancer Chemother Biol Response Modif 2005;22:687-706

14 Dolcetti R, Gloghini A, Caruso A, Carbone A. A lymphomagenic role for HIV beyond immune suppression? Blood 2016;127(11): 1403-1409

15 Corti M, Villafañe M, Bistmans A, Narbaitz M, Gilardi L. Primary extranodal non-hodgkin lymphoma of the head and neck in patients with acquired immunodeficiency syndrome: a clinicopathologic study of 24 patients in a single hospital of infectious diseases in Argentina. Int Arch Otorhinolaryngol 2014;18(3): 260-265

16 Purgina B, Pantanowitz L, Seethala RR. A Review of Carcinomas Arising in the Head and Neck Region in HIV-Positive Patients. Pathol Res Int 2011;2011:469150

17 Zapater E, Bagan JV, Campos A, Armengot M, Abril V, Basterra J. Non-Hodgkin's lymphoma of the head and neck in association with HIV infection. Ann Otolaryngol Chir Cervicofac 1996;113(2): 69-72

18 Finn DG. Lymphoma of the head and neck and acquired immunodeficiency syndrome: clinical investigation and immunohistological study. Laryngoscope 1995; 105(4 Pt 2, Suppl 68)1-18

19 Wood C, Harrington W Jr. AIDS and associated malignancies. Cell Res 2005;15(11-12)947-952

20 Zapater E, Bagán JV, Carbonell F, Basterra J. Malignant lymphoma of the head and neck. Oral Dis 2010;16(2):119-128

21 Weisenburger DD. Epidemiology of non-Hodgkin's lymphoma: recent findings regarding an emerging epidemic. Ann Oncol 1994; 5(Suppl 1)19-24

22 Laskar S, Mohindra P, Gupta S, Shet T, Muckaden MA. Non-Hodgkin lymphoma of the Waldeyer's ring: clinicopathologic and therapeutic issues. Leuk Lymphoma 2008;49(12):2263-2271

23 Nathu RM, Mendenhall NP, Almasri NM, Lynch JW. Non-Hodgkin's lymphoma of the head and neck: a 30-year experience at the University of Florida. Head Neck 1999;21(3):247-254

24 Oluwasanmi AF, Wood SJ, Baldwin DL, Sipaul F. Malignancy in asymmetrical but otherwise normal palatine tonsils. Ear Nose Throat J 2006;85(10):661-663 
25 Kemp S, Gallagher G, Kabani S, Noonan V, O'Hara C. Oral nonHodgkin's lymphoma: review of the literature and World Health Organization classification with reference to 40 cases. Oral Surg Oral Med Oral Pathol Oral Radiol Endod 2008;105(2):194-201

26 Bagan JV, Carbonell F, Gómez MJ, et al. Extra-nodal B-cell nonHodgkin's lymphomas of the head and neck: a study of 68 cases. Am J Otolaryngol 2015;36(1):57-62

27 Levine AM. Acquired immunodeficiency syndrome-related lymphoma. Blood 1992;80(1):8-20

28 Ferrazzo KL, Mesquita RA, Aburad AT, Nunes FD, de Sousa SO. EBV detection in HIV-related oral plasmablastic lymphoma. Oral Dis 2007;13(6):564-569

29 Simo R, Hartley C, Malik T, Wilson GE, Taylor PH, Mandal BK. Primary non-Hodgkin's lymphoma of the larynx in an AIDS patient. J Laryngol Otol 1998;112(1):77-80

30 Weber AL, Rahemtullah A, Ferry JA. Hodgkin and non-Hodgkin lymphoma of the head and neck: clinical, pathologic, and imaging evaluation. Neuroimaging Clin N Am 2003;13(3):371-392

31 Aiken $\mathrm{AH}$, Glastonbury C. Imaging Hodgkin and non-Hodgkin lymphoma in the head and neck. Radiol Clin North Am 2008; 46(2):363-378, ix-X

32 Swedlow SH, Campo E, Harris NL, et al. 2008. Eds. WHO Classification of Tumours of Haematopoietic and Lymphoid Tissues, 4th ed. WHO/International Agency for Research on Cancer: Lyon

33 Boué F, Gabarre J, Gisselbrecht C, et al. Phase II trial of CHOP plus rituximab in patients with HIV-associated non-Hodgkin's lymphoma. J Clin Oncol 2006;24(25):4123-4128

34 Ribera JM, Oriol A, Morgades M, et al; PETHEMA, GELTAMO, GELCAB and GESIDA Groups. Safety and efficacy of cyclophosphamide, adriamycin, vincristine, prednisone and rituximab in patients with human immunodeficiency virus-associated diffuse large B-cell lymphoma: results of a phase II trial. Br J Haematol 2008;140(4):411-419

35 Little RF, Pittaluga S, Grant N, et al. Highly effective treatment of acquired immunodeficiency syndrome-related lymphoma with dose-adjusted EPOCH: impact of antiretroviral therapy suspension and tumor biology. Blood 2003;101(12):4653-4659

36 Barta SK, Lee JY, Kaplan LD, Noy A, Sparano JA. Pooled analysis of AIDS malignancy consortium trials evaluating rituximab plus CHOP or infusional EPOCH chemotherapy in HIV-associated non-Hodgkin lymphoma. Cancer 2012;118(16):3977-3983

37 Sparano JA, Lee S, Chen MG, et al. Phase II trial of infusional cyclophosphamide, doxorubicin, and etoposide in patients with HIV-associated non-Hodgkin's lymphoma: an Eastern Cooperative Oncology Group Trial (E1494). J Clin Oncol 2004;22(8):1491-1500

38 Spina M, Jaeger U, Sparano JA, et al. Rituximab plus infusional cyclophosphamide, doxorubicin, and etoposide in HIV-associated non-Hodgkin lymphoma: pooled results from 3 phase 2 trials. Blood 2005;105(5):1891-1897

39 Spina M, Simonelli C, Vaccher E, et al. Long-term follow-up of rituximab and infusional cyclophosphamide, doxorubicin, and etoposide (CDE) in combination with HAART in HIV related Non-Hodgkin Lymphomas (NHL) [abstract]. Blood 2008; 1467:112available at: http://www.bloodjournal.org/content/ $112 / 11 / 1467$

40 Cortes J, Thomas D, Rios A, et al. Hyperfractionated cyclophosphamide, vincristine, doxorubicin, and dexamethasone and highly active antiretroviral therapy for patients with acquired immunodeficiency syndrome-related Burkitt lymphoma/leukemia. Cancer 2002;94(5):1492-1499

41 Thomas DA, Faderl S, O'Brien S, et al. Chemoimmunotherapy with hyper-CVAD plus rituximab for the treatment of adult Burkitt and Burkitt-type lymphoma or acute lymphoblastic leukemia. Cancer 2006;106(7):1569-1580

42 Thomas DA, Kantarjian HM, Cortes J, et al. Long-term outcome after hyper-CVAD and rituximab chemoimmunotherapy for Burkitt (BL) or Burkitt-like (BLL) leukemia/lymphoma and mature Bcell acute lymphocytic luekemia (ALL) [abstract]. Blood 2008; 1929:112available at: http://www.bloodjournal.org/content/ $112 / 11 / 1929$

43 Wang ES, Straus DJ, Teruya-Feldstein J, et al. Intensive chemotherapy with cyclophosphamide, doxorubicin, high-dose methotrexate/ifosfamide, etoposide, and high-dose cytarabine (CODOX-M/ IVAC) for human immunodeficiency virus-associated Burkitt lymphoma. Cancer 2003;98(6):1196-1205

44 Barnes JA, Lacasce AS, Feng Y, et al. Evaluation of the addition of rituximab to CODOX-M/IVAC for Burkitt's lymphoma: a retrospective analysis. Ann Oncol 2011;22(8):1859-1864

45 Noy A, Kaplan L, Lee J, et al. Modified dose intensive R-CODOX-M/ IVAC for HIV-associated Burkitt (BL) (AMC 048) shows efficacy and tolerability, and predictive potential of IRF4/MUM1 expression. Infect Agent Cancer 2012;7(Suppl 1):14

46 Castillo JJ, Bibas M, Miranda RN. The biology and treatment of plasmablastic lymphoma. Blood 2015;125(15):2323-2330

47 Dunleavy K, Pittaluga S, Czuczman MS, et al. Differential efficacy of bortezomib plus chemotherapy within molecular subtypes of diffuse large B-cell lymphoma. Blood 2009;113(24):6069-6076

48 Okada S, Goto H, Yotsumoto M. Current status of treatment for primary effusion lymphoma. Intractable Rare Dis Res 2014;3(3): 65-74

49 Hocqueloux L, Agbalika F, Oksenhendler E, Molina JM. Long-term remission of an AIDS-related primary effusion lymphoma with antiviral therapy. AIDS 2001;15(2):280-282

50 Luppi M, Trovato R, Barozzi P, et al. Treatment of herpesvirus associated primary effusion lymphoma with intracavity cidofovir. Leukemia 2005;19(3):473-476

51 Halfdanarson TR, Markovic SN, Kalokhe U, Luppi M. A nonchemotherapy treatment of a primary effusion lymphoma: durable remission after intracavitary cidofovir in HIV negative PEL refractory to chemotherapy. Ann Oncol 2006;17(12):1849-1850

52 Hentrich M, Berger M, Wyen C, et al. Stage-adapted treatment of HIV-associated Hodgkin lymphoma: results of a prospective multicenter study. J Clin Oncol 2012;30(33):4117-4123

53 Kim SJ, Kim WS. Treatment of localized extranodal NK/T cell lymphoma, nasal type. Int J Hematol 2010;92(5):690-696

54 Wang ZY, Li YX, Wang WH, et al. Primary radiotherapy showed favorable outcome in treating extranodal nasal-type NK/T-cell lymphoma in children and adolescents. Blood 2009;114(23): 4771-4776

55 Kim WS, Song SY, Ahn YC, et al. CHOP followed by involved field radiation: is it optimal for localized nasal natural killer/T-cell lymphoma? Ann Oncol 2001;12(3):349-352

56 Kim SJ, Kim K, Kim BS, et al. Phase II trial of concurrent radiation and weekly cisplatin followed by VIPD chemotherapy in newly diagnosed, stage IE to IIE, nasal, extranodal NK/T-Cell Lymphoma: Consortium for Improving Survival of Lymphoma study. J Clin Oncol 2009;27(35):6027-6032

57 Yamaguchi M, Tobinai K, Oguchi M, et al. Concurrent chemoradiotherapy for localized nasal natural killer/T-cell lymphoma: an updated analysis of the Japan clinical oncology group study JCOG0211. J Clin Oncol 2012;30(32):4044-4046

58 Jiang M, Zhang H, Jiang Y, et al. Phase 2 trial of "sandwich" Lasparaginase, vincristine, and prednisone chemotherapy with radiotherapy in newly diagnosed, stage IE to IIE, nasal type, extranodal natural killer/T-cell lymphoma. Cancer 2012; 118(13):3294-3301

59 Levine AM, Sadeghi S, Espina B, Tulpule A, Nathwani B. Characteristics of indolent non-Hodgkin lymphoma in patients with type 1 human immunodeficiency virus infection. Cancer 2002;94(5):1500-1506

60 Hermans J, Krol AD, van Groningen K, et al. International Prognostic Index for aggressive non-Hodgkin's lymphoma is valid for all malignancy grades. Blood 1995;86(4):1460-1463

61 Ziepert M, Hasenclever D, Kuhnt E, et al. Standard International prognostic index remains a valid predictor of outcome for patients with aggressive CD20+ B-cell lymphoma in the rituximab era. J Clin Oncol 2010;28(14):2373-2380 
62 Corey JP, Seligman I. Otolaryngology problems in the immune compromised patient-an evolving natural history. Otolaryngol Head Neck Surg 1991;104(2):196-203

63 Leess FR, Kessler DJ, Mickel RA. Non-Hodgkin's lymphoma of the head and neck in patients with AIDS. Arch Otolaryngol Head Neck Surg 1987;113(10):1104-1106

64 Bell DM. Occupational risk of human immunodeficiency virus infection in healthcare workers: an overview. Am J Med 1997; 102(5B):9-15

65 Ippolito G, Puro V, De Carli G. The risk of occupational human immunodeficiency virus infection in health care workers. Italian Multicenter Study. The Italian Study Group on Occupational Risk of HIV infection. Arch Intern Med 1993;153(12):1451-1458

66 Haines T, Stringer B, Herring J, Thoma A, Harris KA. Surgeons' and residents' double-gloving practices at 2 teaching hospitals in Ontario. Can J Surg 2011;54(2):95-100

67 Mischke C, Verbeek JH, Saarto A, Lavoie MC, Pahwa M, Ijaz S. Gloves, extra gloves or special types of gloves for preventing percutaneous exposure injuries in healthcare personnel. Cochrane Database Syst Rev 2014;3(3):CD009573
68 Parantainen A, Verbeek JH, Lavoie MC, Pahwa M. Blunt versus sharp suture needles for preventing percutaneous exposure incidents in surgical staff. Cochrane Database Syst Rev 2011;(11):CD009170

69 Kuhar DT, Henderson DK, Struble KA, et al. US Public Health Service Working Group.Updated US Public Health Service guidelines for the management of occupational exposures to human immunodeficiency virus and recommendations for postexposure prophylaxis. Infect Control Hosp Epidemiol 2013;34(9):875-892

70 Ihrler S, Zietz C, Riederer A, Diebold J, Löhrs U. HIV-related parotid lymphoepithelial cysts. Immunohistochemistry and 3-D reconstruction of surgical and autopsy material with special reference to formal pathogenesis. Virchows Arch 1996;429(2-3)139-147

71 Greaves WO, Wang SA. Selected topics on lymphoid lesions in the head and neck regions. Head Neck Pathol 2011;5(1):41-50

72 Fishleder A, Tubbs R, Hesse B, Levine H. Uniform detection of immunoglobulin-gene rearrangement in benign lymphoepithelial lesions. N Engl J Med 1987;316(18):1118-1121

73 Barta SK, Xue X, Wang D, et al. A new prognostic score for AIDSrelated lymphomas in the rituximab-era. Haematologica 2014; 99(11):1731-1737 